\title{
Feasibility of a tailored home-based exercise intervention during neoadjuvant chemotherapy in breast cancer patients
}

\author{
Kathleen M. Sturgeon ${ }^{1,5^{*} \mathbb{D}}$, Amanda M. Smith², Elizabeth H. Federici ${ }^{3}$, Namratha Kodali ${ }^{3}$, Renée Kessler ${ }^{4}$, \\ Edward Wyluda ${ }^{3}$, Leah V. Cream ${ }^{3}$, Bonnie Ky ${ }^{2}$ and Kathryn H. Schmitz ${ }^{1}$
}

\begin{abstract}
Purpose: To evaluate the feasibility of a home-based moderate-to-vigorous intensity, phased (introduction, intermediate, maintenance), exercise prescription in breast cancer patients receiving cardiotoxic neoadjuvant chemotherapy.

Methods: Nineteen breast cancer patients were randomized to intervention or control for the duration of chemotherapy (16-24 weeks). The intervention was one aerobic exercise session at 80-90\% VO 2 max for $25 \mathrm{~min} /$ week and $65 \%-75 \% \mathrm{VO}_{2 \max }$ for $\geq 50 \mathrm{~min} /$ week. Adherence to the tailored home-based program was assessed by heart rate monitors. Acceptability, tolerability, feasibility, efficacy, change in $\mathrm{VO}_{2 \text { max }}$ and patient reported outcomes, safety, and clinical events were assessed.

Results: $25.7 \%$ of eligible women consented (acceptability). Adherence was $87.6 \%$. Women were not able to maintain exercise intensity as chemotherapy progressed (23.7\% of exercise minutes were completed at prescribed heart rate during maintenance). Efficacy of the intervention was demonstrated by maintenance of $\mathrm{VO}_{2 \max }(-1.0 \pm 13.2 \%)$ compared to $(-27.5 \pm 7.4 \%)$ the control group. Further, during and after therapy, patients in the intervention arm reported less fatigue (control-baseline: $14.4 \pm 15.9$; midpoint: $19.0 \pm 11.4$; follow-up: $29.4 \pm 20.0$; intervention-baseline: 29.2 \pm 24.6; midpoint: $24.6 \pm 14.4$; follow-up: $23.6 \pm 11.9$ ), impairment in activities (control-baseline: $13.7 \pm 16.0$; midpoint: $32.8 \pm 17.0$; follow-up: 58.6 \pm 27.9 ; intervention-baseline: $38.7 \pm 31.8$; midpoint: $47.1 \pm 27.5$; follow-up: $47.5 \pm 31.0$ ), and pain (control-baseline: $80.8 \pm 17.1$; midpoint: $73.9 \pm 20.7$; follow-up: $50.7 \pm 25.7$; intervention-baseline: 68.7 \pm 28.4; midpoint: 61.4 \pm 22.5 ; follow-up: 65.3 \pm 22.4 ). There were no differences in adverse events, treatment delays, or pathological complete response.
\end{abstract}

Conclusions: Neoadjuvant breast cancer patients maintained approximately one hour/week of moderate-intensity exercise over the course of their treatment. Further, this volume of exercise was sufficient to maintain fitness capacity and quality of life compared to the control group.

Trial registry: ClinicalTrials.gov Identifier: NCT03280836, prospectively registered 9/13/2017, https://clinicaltrials.gov/ ct2/show/NCT03280836.

Keywords: Aerobic exercise, Home-based, Drug therapy, Quality of life, Fitness

*Correspondence: Kms99@psu.edu

${ }^{1}$ Department of Public Health Sciences, Penn State College of Medicine, Hershey, PA, USA

Full list of author information is available at the end of the article

\section{Background}

Breast cancer continues to be the leading site of new cancer cases for women in the United States. It is estimated that in 2019, 268,600 women were diagnosed with breast cancer [1]. The trend in annual rates of new breast cancer original author(s) and the source, provide a link to the Creative Commons licence, and indicate if changes were made. The images or other third party material in this article are included in the article's Creative Commons licence, unless indicated otherwise in a credit line to the material. If material is not included in the article's Creative Commons licence and your intended use is not permitted by statutory regulation or exceeds the permitted use, you will need to obtain permission directly from the copyright holder. To view a copy of this licence, visit http://creativecommons.org/licenses/by/4.0/. The Creative Commons Public Domain Dedication waiver (http://creativeco mmons.org/publicdomain/zero/1.0/) applies to the data made available in this article, unless otherwise stated in a credit line to the data. 
cases has remained largely unchanged in the last 20 years. Uptake in screening practices and improved treatment have contributed to an increasing pool of breast cancer survivors. While 5-year cancer-specific survival rates in early-stage breast cancer patients are 90-100\%, [2] patients diagnosed with locally advanced breast cancer, or, breast cancer patients with an aggressive tumor subtype, have worse outcomes. Five-year disease-free survival rates for locally advanced, [3] ER+/PR+/HER2- or HER2+, [4] and TNBC [4] are 85\%, 78\%, and 69\% respectively. These statistics highlight that (1) breast cancer continues to affect many women in the United States, (2) this trend remains unchanged, (3) the number of breast cancer survivors is increasing, and (4) there is room for improvement for patients with worse prognostic indicators. Additionally, side effects of cancer treatment, such as cardiotoxicity, may predispose breast cancer patients to increased risk of mortality from cardiovascular disease compared to the general United States population [5].

Our pilot study used exercise as a non-pharmacological intervention to improve treatment-related outcomes in breast cancer patients with worse prognostic indicators. Neoadjuvant chemotherapy is a standard of breast cancer clinical care for several tumor types: locally advanced tumors, HER2+ tumors, and TNBC [6]. These tumor types also have the poorest relapse-free survival rates. Pre-clinical work demonstrates exercise-induced improvement in tumor response to chemotherapy [7]. We and others have reported exercise-induced improvements in tumor perfusion leading to greater efficacy of chemotherapy in mice $[7,8]$. However, it is unknown if exercise clinically reduces tumor burden or improves therapeutic efficacy. There is also uncertainty as to the dose of exercise appropriate for hypothesized exerciseinduced improvements in therapeutic efficacy in humans.

The dose of exercise required to improve therapeutic efficacy may differ from the dose of exercise required to protect the heart against cardiotoxic chemotherapies. Indeed, we observed that while a low-to-moderate level of exercise failed to mitigate cardiac remodeling due to doxorubicin in tumor bearing animals, [9] this low-tomoderate level of exercise in mice did improve therapeutic efficacy [7, 9]. Based on previous work in cardiology, the threshold dose of exercise for cardiac benefit may be found at higher intensities [10]. Yet, moderate-to-vigorous intensity exercise may not be feasible in breast cancer patients actively receiving chemotherapy. The 2019 American College of Sports Medicine (ACSM) expert panel on exercise in cancer highlighted that an individual's response to a given exercise stimulus may vary due to the direct effects of cancer treatments on physiological systems (e.g., anemia), side effects of cancer treatment (e.g., cancer-related fatigue may lower exercise tolerance), or demographics factors (e.g., age) [11, 12]. Furthermore, during active treatment an individual's ability to tolerate exercise may fluctuate from day to day or week to week.

Designing exercise oncology interventions that work for breast cancer patients is important because cancer patients tend to present at diagnosis with lower fitness capacity $(-17 \%)$ compared to healthy, sedentary, similar aged, women [13]. Fitness capacity becomes further impaired $(-10 \%)$ following cancer treatment [13]. This decline is sustained for years after treatment compared to age-matched controls [14]. These findings are of key importance given that even small differences in fitness capacity (1 MET or $3.5 \mathrm{~mL} / \mathrm{kg} / \mathrm{min}$ ) are associated with a significantly higher risk for cardiovascular mortality $(18 \%)[15,16]$. Therefore, an intervention during neoadjuvant chemotherapy to maintain fitness capacity and mitigate declines in fitness capacity is a clinically meaningful approach to decrease risk of overall and cardiovascular specific mortality in breast cancer patients [5, 16-18].

While exercise is a meaningful complementary approach during cancer treatment, it may also be an overwhelming addition to already significant time and resource burdens on neoadjuvant breast cancer patients. Appointments at hematology/oncology, phlebotomy, and the infusion suite are often interspersed with planning appointments with surgical oncology, plastics and reconstructive surgery, and radiation oncology. Thus, homebased exercise interventions, rather than supervised programs, have fewer logistical barriers for uptake [12]. In addition, while it is known supervised exercise is more efficacious, there is still biological benefit to home-based exercise [11]. Strong evidence supports the benefits of exercise oncology during cancer treatment for decreased fatigue, improved health related quality of life, and increased physical function [11]. Yet, there is currently insufficient evidence regarding the benefit of exercise oncology for outcomes such as pain, work productivity, and treatment tolerance [11].

Ongoing work in our laboratory and others utilizes pre-clinical models to determine optimal dosing strategies for exercise oncology to achieve specific outcomes (therapeutic efficacy or cardiotoxicity) [7-9]. In order to translate results to the clinical setting we conducted a multi-center pilot study to examine the feasibility of a moderate-to-vigorous, home-based, remotely delivered, exercise program in breast cancer patients who were initiating neoadjuvant chemotherapy. We hypothesized that a tailored, phased, moderate-to-vigorous intensity, exercise prescription conducted from first to final chemotherapy infusion, and weekly tele-coaching would be acceptable, tolerable, feasible, and efficacious in mitigating treatment-related side effects. 


\section{Methods}

\section{Sample population and recruitment}

Nineteen female non-metastatic breast cancer patients who were scheduled to receive neoadjuvant chemotherapy were enrolled across three sites between 2017 and 2020. Identification of eligible patients occurred at the Penn State Cancer Institute (PSCI, Hershey, PA), Andrews \& Patel community oncology practice (A\&P, Harrisburg, PA), and the University of Pennsylvania (UPenn, Abramson Cancer Center, Philadelphia PA). The study was approved by the Penn State College of Medicine Institutional Review Board and written informed consent was obtained prior to any study procedures. Inclusion criteria included: Breast cancer stage I-III, English speaking patients, $>18$ years with documented breast cancer for whom treatment with cardiotoxic chemotherapy regimens was planned (Taxotere, Carboplatin, Herceptin + Perjeta; $\mathrm{TCH}+\mathrm{P}$, or, Adriamycin, cyclophosphamide, Taxol; ACT). Exclusion criteria included pregnancy, presence of heart disease, or previous history of anthracycline chemotherapy. Approval to approach the patient was approved by the primary medical oncologist. Additional eligibility criteria was confirmed by interview prior to consent (absence of heart disease, no contraindications for exercise testing or training, and sedentary defined as $<75 \mathrm{~min} /$ wk of self-reported moderate intensity leisure-time physical activity over the past month). Acceptability was defined as the consent rate amongst eligible patients.

The study was powered at $80 \%$ to detect at $4 \mathrm{ml} / \mathrm{kg} /$ min difference in $\mathrm{VO}_{2 \max }$ between control and intervention groups $(n=20)$ at an alpha level of 0.05 [19]. Four $\mathrm{ml} / \mathrm{kg} / \mathrm{min}$ is $\sim$ equivalent to a 1 -MET difference, which has been associated with a $23 \%$ reduction in risk for cardiovascular events in women [20]. The study was closed to recruitment at $\mathrm{n}=19$ due to the COVID-19 pandemic (resulting in $78 \%$ power).

\section{Primary endpoint}

For safety reasons, submaximal fitness testing was conducted with 10-lead ECG cardiac monitoring with expired gas analysis (ParvoMedics TrueOne ${ }^{\circledR} 2400$, Sandy UT) [21]. Patients were asked to complete a modified Bruce Protocol to volitional fatigue or through the protocol stage where $80 \%$ heart rate maximum $\left(\mathrm{HR}_{\max }\right)$ was reached. The same measurement technicians conducted baseline and follow up fitness testing. Blood pressure was measured and rating of perceived exertion (RPE) on the modified Borg Scale was evaluated two minutes into each protocol stage. Testing was conducted before starting chemotherapy and in the window following chemotherapy but prior to surgical resection. $\mathrm{VO}_{2 \max }$ was predicted at age-adjusted $\mathrm{HR}_{\max }$ using the Tanaka formula and the individual linear slope generated from graphing $\mathrm{VO}_{2}$ and HR from the submaximal test on their respective graphical axis $[22,23]$.

\section{Measurements}

Following baseline $\mathrm{VO}_{2 \max }$ testing patients were randomized 1:1 using an a priori computer-generated sequence. Patients engaged in an exercise education session before they received intervention materials on exercise training. The education session provided instruction regarding proper warm-up, cool-down, stretches, proper footwear for injury prevention, and understanding RPE [24]. For women randomized to the intervention arm, this education session took place at their baseline exercise testing session. For women randomized to the control arm, this education session took place at their follow up exercise testing session.

Surveys and questionnaires were also collected at baseline, midpoint, and follow up. Midpoint was week 8 or 9 depending on chemotherapy regimen. Patients completed the Godin Physical Activity Questionnaire, Work Productivity and Activity Impairment Questionnaire (WPAI), EuroQol 5D (EQ-5D), RAND 36-Item Short Form (SF-36), and the Multidimensional Fatigue Symptom Inventory (MFSI-SF) short form, and an adverse events survey [25-28]. The Leisure Score Index from the Godin Physical Activity Questionnaire was calculated as previously described [25]. Additionally, at follow up, patients completed an injury history questionnaire to detect any exercise-related events [29]. Throughout the intervention, electronic medical records and personal communications with patients were monitored for deviations from normal health (adverse events) and documented. Electronic medical records were monitored for changes to treatment schedule and synoptic pathology reports were abstracted following surgical resection.

\section{Control}

Participants randomized to the control group were asked to maintain their usual level of physical activity and to not engage in any new exercise program during study participation. Participants in the control group were given the exercise DVD, exercise binder, and exercise prescription based on their follow up exercise test, following completion of all study visits (including their exercise safety education session), and clearance from surgical oncology.

\section{Intervention}

Patients randomized to the intervention group received three commercially available aerobics DVDs and an informational binder of aerobic exercises. Patients were instructed to self-select the combination of activities that places them in their appropriate heart rate zone. Patients 
were coached by the exercise interventionist on this during their education session and throughout the intervention. Phone calls with the coach were conducted $1 \mathrm{x} /$ week, and typically lasted 10-20 min. All participants interacted with the same exercise interventionist and calls revolved around discussions of: review of weekly progress from HR monitors and self-report logs, HR and duration of exercise goals for the next week, discovery of daily activities/time use to identify strategies and opportunities to address challenges or barriers to exercise, general side effects of chemotherapy treatment, and adaptation of the exercise program to the course of side effects and daily life.

The DVDs and binder included exercises ranging from continuous in-home walking routines (for rainy/cold days or those with limitations for outside activities) to higher intensity continuous aerobic activities such as step taps, skipping, and jumping jacks (with modifications/ variations shown). The DVD titles were: START! Walking At Home ${ }^{\circledR}$ with Leslie Sansone; Just Walk, 5 Boosted Miles with Leslie Sansone; and 5 Mix \& Match Miles with Jessica Smith. The movements in the DVDs were aerobic and combinations of: marching in place, side touches, step taps, knee lifts, front/back kicks, hamstring curls, walking forward and backward, jogging in place, skater hops, grapevine, arm swings, overhead reaches, clapping, front presses, and arm rows.

Patients wore a Polar Heart Rate monitor (US model RS400, Polar Electro Inc., Lake Success, NY) during exercise to monitor exercise intensity. The study interventionist reviewed data from the heart rate monitors to objectively monitor exercise adherence. Patients in the intervention group were also asked to keep an exercise log with the date, time, average heart rate obtained from a heart rate monitor, duration of workout and stretching, and any comments regarding the workout. Logs were also reviewed weekly by the interventionist and discussed on the weekly coaching call [30].

The exercise intervention was designed to target $75 \mathrm{~min}$ per week of aerobic activity at $70-90 \%$ of baseline $\mathrm{VO}_{2 \max }$, or associated RPE. In Weeks 1-4 (Introductory Phase) of the program, the frequency, duration, and intensity of aerobic exercise was progressively increased from an initial prescription of $60 \mathrm{~min} / \mathrm{wk}$ (intervention frequency was suggested at 3 sessions/wk, but allowed to be broken up into other increments for the entirety of the intervention) at $50 \%$ of $\mathrm{VO}_{2 \max }(\mathrm{RPE}=2)$, up to $75+\mathrm{min} /$ wk at $60 \%$ of $\mathrm{VO}_{2 \max }(\mathrm{RPE}=3-4)$ at the end of week 4 . The goal of these sessions was to introduce aerobic exercise, including warm-up and proper form as well as integration with lifestyle.

In weeks 5-11 (Intermediate Phase), the goal was to increase exercise intensity from 60 to $80 \% \mathrm{VO}_{2 \max }$ in a ramped fashion. Specifically, by week 11, the exercise prescription was $65-75 \% \mathrm{VO}_{2 \max }(\mathrm{RPE}=5-6)$ for two sessions per week (or $2 / 3 \mathrm{~s}$ of weekly exercise time) and in the remaining session (or $1 / 3$ of weekly exercise time), aerobic exercise intensity was $80 \%+\mathrm{VO}_{2 \max }(\mathrm{RPE}=7-8)$. In weeks 12-24 (Maintenance Phase) participants were asked to maintain the exercise prescription from week 11. This tailored exercise prescription was based on initial $\mathrm{VO}_{2 \max }$ and delivered through personal heart rate zones. During the maintenance phase, if side effects of chemotherapy limited the ability of patients to reach their heart rate goal, they were encouraged to work at the RPE associated with the HR zone.

\section{Statistical analysis}

Descriptive statistics were reported for baseline variables including percentages for categorical variables and means and standard deviations for continuous variables. Acceptability was defined by the proportion of approached patients whom consented to the study. Tolerability was defined (1) by the number of weekly exercise minutes completed, and (2) by the number of weekly exercise minutes completed at the prescribed exercise intensity according to the patient's HR monitor. Selfreported exercise time in the patient log book was utilized in certain instances (malfunctioning watch, missed wear) to determine weekly exercise minutes only if $80 \%$ of their log entries could be validated against the heart rate monitor data. Feasibility was defined by the loss to follow up for final measurements $\left(\mathrm{VO}_{2 \max }\right.$ and patient reported outcome questionnaires). In addition to these pilot study observations, the primary outcome, and efficacy of the intervention, was difference in fitness capacity between the intervention and control groups at the follow up exercise test [21]. Baseline adjusted linear regression was used to assess differences between groups at the follow up exercise test. A mixed-model repeated measures analysis of variance was used to compare between group differences over time for the secondary outcome survey variables. Fisher's exact tests and $x^{2}$-tests were used to examine between group differences in categorical variables and significance level was set at $P<0.05$.

\section{Results}

Figure 1 provides the CONSORT diagram for the trial. Patients were identified by screening schedules of breast oncologists for patients recommended for neoadjuvant chemotherapy. Overall, 155 women were assessed for eligibility ( $n=77$ UPenn, $n=61$ PSCI, $n=17$ A\&P). The number of patients meeting certain exclusion criteria varied between sites. Specifically, co-enrollment on a clinical trial was only observed for patients at UPenn $(n=16)$ and $65 \%$ of the patients that failed 


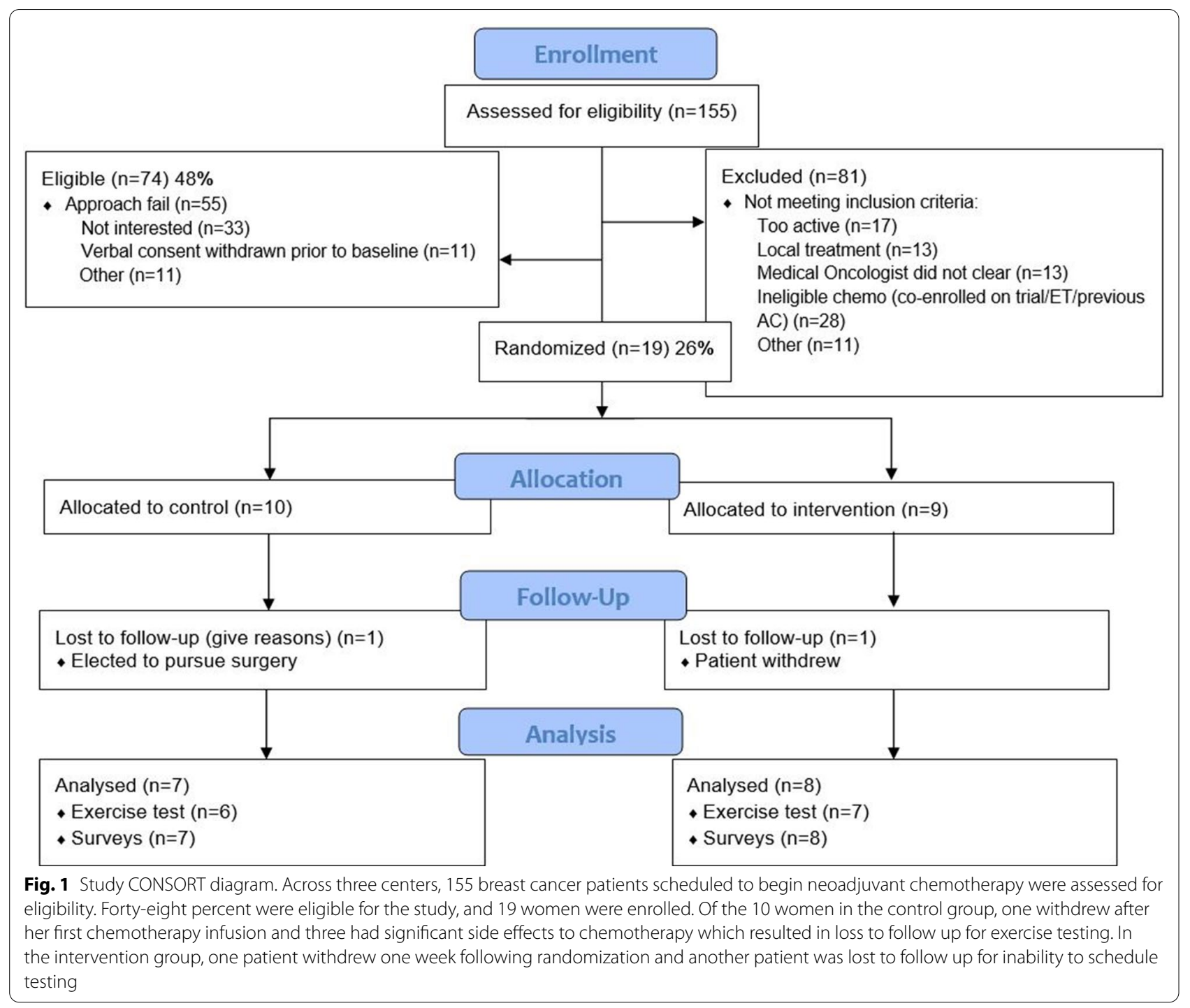

eligibility screening due to high physical activity levels were screened at UPenn. Overall, our acceptability rate was $25.7 \%$ with 19 women consented of 74 eligible women that were approached. We observed that while we obtained verbal consent from 30 women (40.5\%) that were eligible, there was a $15 \%$ withdraw rate of verbal consent due to being overwhelmed with their cancer diagnosis prior to starting chemotherapy, in addition to the burden of appointments, and altered daily life course. Two patients withdrew from the study within the first chemotherapy cycle. Feasibility for the primary outcome of $\mathrm{VO}_{2 \max }$ was $68 \%$ (10.5\% withdrew, $5.3 \%$ loss to follow up, $15.8 \%$ chemotherapy-induced contraindications to exercise testing), and $79 \%$ completed final surveys $(10.5 \%$ withdrew, 10.5\% loss to follow up). Figure 2 displays the timeline of research activities compared to clinical care milestones (start/end of chemotherapy).

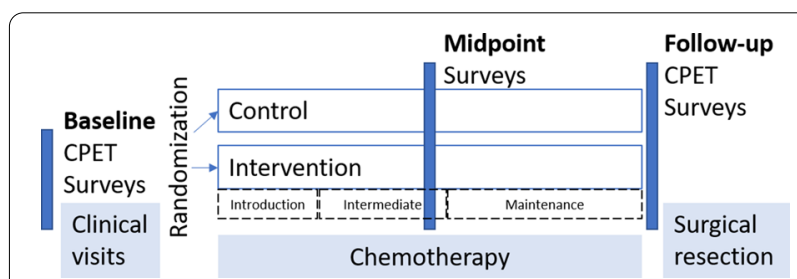

Fig. 2 Study schema of research activities and neoadjuvant chemotherapy. All baseline testing (cardiopulmonary exercise test (CPET) and surveys) was conducted prior to starting chemotherapy and the exercise intervention was initiated concomitant to chemotherapy. Follow up testing was completed prior to surgical resection. Chemotherapy treatment lasted 16-24 weeks depending on treatment and individual delays. The introductory phase of the intervention lasted 4 weeks, followed by 7 weeks of an intermediate ramp phase. At week 12 the maintenance phase began and continued until chemotherapy and follow-up testing was completed 
Table 1 Demographic and clinical characteristics

\begin{tabular}{|c|c|c|c|c|}
\hline & Overall $n=19$ & Control $n=10$ & Intervention $\mathrm{n}=\mathbf{9}$ & $P$-value \\
\hline Age (years) & $49.4 \pm 10.5$ & $51.5 \pm 9.5$ & $47.0 \pm 11.7$ & 0.37 \\
\hline \multicolumn{5}{|l|}{ Race $n,(\%)$} \\
\hline White & $13(69 \%)$ & $8(80 \%)$ & $5(56 \%)$ & \multirow[t]{3}{*}{0.40} \\
\hline Black & $5(26 \%)$ & $2(20 \%)$ & $3(33 \%)$ & \\
\hline Other & $1(5 \%)$ & $0(0 \%)$ & $1(11 \%)$ & \\
\hline \multicolumn{5}{|l|}{ Ethnicity n, (\%) } \\
\hline Not hispanic & $19(100 \%)$ & $10(100 \%)$ & $9(100 \%)$ & \\
\hline \multicolumn{5}{|l|}{ Working status n, (\%) } \\
\hline Full time (at least 1 job) & 12 (63\%) & $7(70 \%)$ & $5(56 \%)$ & \multirow[t]{3}{*}{0.73} \\
\hline Part time (no FT) & $4(21 \%)$ & $2(20 \%)$ & $2(22 \%)$ & \\
\hline Other & $3(16 \%)$ & $1(10 \%)$ & $2(22 \%)$ & \\
\hline \multicolumn{5}{|l|}{ Household income n, (\%) } \\
\hline $0-49,999$ & $5(26 \%)$ & $3(30 \%)$ & $2(22 \%)$ & \multirow[t]{4}{*}{0.18} \\
\hline $50,000-75,000$ & $4(21 \%)$ & $3(30 \%)$ & $1(11 \%)$ & \\
\hline $75,001-125,000$ & $6(32 \%)$ & $1(10 \%)$ & $5(56 \%)$ & \\
\hline $125,000+$ & $4(21 \%)$ & $3(30 \%)$ & $1(11 \%)$ & \\
\hline \multicolumn{5}{|l|}{ Education n, (\%) } \\
\hline HS/some college & $4(21 \%)$ & $2(20 \%)$ & $2(22 \%)$ & \multirow[t]{3}{*}{0.74} \\
\hline Associates/Bachelors & $8(42 \%)$ & $5(50 \%)$ & $3(33 \%)$ & \\
\hline Graduate school & $7(37 \%)$ & $3(30 \%)$ & $4(44 \%)$ & \\
\hline \multicolumn{5}{|l|}{ Partnered n, (\%) } \\
\hline Not partnered & $5(26 \%)$ & $4(40 \%)$ & $1(11 \%)$ & \multirow[t]{2}{*}{0.15} \\
\hline Coupled & $14(74 \%)$ & $6(60 \%)$ & $8(89 \%)$ & \\
\hline \multicolumn{5}{|l|}{ Smoking status n, (\%) } \\
\hline Non or ex-smoker & 16 (84\%) & $9(90 \%)$ & $7(78 \%)$ & \multirow[t]{2}{*}{0.53} \\
\hline Current smoker & $3(16 \%)$ & $1(10 \%)$ & $2(22 \%)$ & \\
\hline \multicolumn{5}{|l|}{ Site $n,(\%)$} \\
\hline $\mathrm{CCC}$ & $6(32 \%)$ & $3(30 \%)$ & $3(33 \%)$ & \multirow[t]{3}{*}{0.97} \\
\hline $\mathrm{Cl}$ & $9(47 \%)$ & $5(50 \%)$ & $4(44 \%)$ & \\
\hline Community & $4(21 \%)$ & $2(20 \%)$ & $2(22 \%)$ & \\
\hline \multicolumn{5}{|l|}{ Stage n, (\%) } \\
\hline 1 & 4 (21\%) & $2(20 \%)$ & $2(22 \%)$ & \multirow[t]{3}{*}{0.93} \\
\hline 2 & $10(53 \%)$ & $5(50 \%)$ & $5(55 \%)$ & \\
\hline 3 & $5(26 \%)$ & $3(30 \%)$ & $2(22 \%)$ & \\
\hline \multicolumn{5}{|l|}{ Tumor type n, (\%) } \\
\hline HR+ HER2+ & $6(32 \%)$ & $4(40 \%)$ & $2(22 \%)$ & \multirow[t]{4}{*}{0.81} \\
\hline $\mathrm{HR}+\mathrm{HER} 2-$ & $2(11 \%)$ & $1(10 \%)$ & $1(11 \%)$ & \\
\hline HR-HER2+ & $8(42 \%)$ & $4(40 \%)$ & $4(44 \%)$ & \\
\hline HR-HER2- & $3(16 \%)$ & $1(10 \%)$ & $2(22 \%)$ & \\
\hline \multicolumn{5}{|l|}{ Chemo n, (\%) } \\
\hline $\mathrm{ACT}$ & $5(26 \%)$ & $2(20 \%)$ & $3(33 \%)$ & \multirow[t]{3}{*}{0.51} \\
\hline $\mathrm{TCHP}$ & $9(47 \%)$ & $6(60 \%)$ & $3(33 \%)$ & \\
\hline ACTH & $5(26 \%)$ & $2(20 \%)$ & $3(33 \%)$ & \\
\hline
\end{tabular}

Data presented as mean \pm SD for continuous data and $\mathrm{n}(\%)$ for categorical data. Abbreviations include: Comprehensive Cancer Center (CCC), Cancer Institute (Cl), hormone receptor (HR), human epidermal growth factor receptor 2 (HER2), ACT denotes Adriamycin ${ }^{\circledR}$ (doxorubicin), cyclophosphamide, and Taxol ${ }^{\circledR}$ (paclitaxel), TCHP denotes Taxotere ${ }^{\circledR}$ (docetaxel), carboplatin, Herceptin ${ }^{\circledast}$ (trastuzumab), Perjeta ${ }^{\circledR}$ (pertuzumab) 
The study demographic ranged in age from 26 to 64 years and was $31 \%$ minority and $100 \%$ non-Hispanic (Table 1). At baseline, $84 \%$ of women were working full or part-time, and $53 \%$ had household incomes greater than $\$ 75,000$. The majority of the women were coupled (74\%), non- or ex-smokers (84\%). Clinically, the majority of women had stage 2 breast cancer and were HER2+ (74\%). There were no significant differences in distribution of demographic or clinical characteristics between the intervention and control groups (Table 1).

Of the nine patients in the exercise intervention group, one withdrew prior to starting, and two did not participate past week two. Of the six women that engaged in the exercise training, we observed that it was very difficult for patients to maintain the prescribed exercise intensity during the maintenance phase of the exercise program (Table 2). However, they were able to maintain a schedule of over an hour of exercise per week. While not all of that time exercising was spent at the prescribed heart rate (exercise intensity), it was over $85 \%$ of the prescribed exercise duration. The observed heart rates were on average consistent with exercising at $60-65 \%$ of $\mathrm{VO}_{2 \max }$ for the entire intervention.

The intervention was sufficient in maintaining fitness capacity (baseline: $19.5 \pm 5.9 \mathrm{ml} / \mathrm{kg} / \mathrm{min}$; follow up: $18.9 \pm 5.8 \mathrm{ml} / \mathrm{kg} / \mathrm{min}$ ), whereas patients in the control group saw a significant decrease (baseline: $18.5 \pm 3.7 \mathrm{ml} /$ $\mathrm{kg} / \mathrm{min}$; follow up: $14.9 \pm 3.0 \mathrm{ml} / \mathrm{kg} / \mathrm{min}$ ) in their fitness capacity (Fig. 3). Estimated $\mathrm{VO}_{2 \max }$ decreased from baseline by $-24.5 \%$ in the control group and by $-1.7 \%$ in the intervention group. The exercise intervention significantly increased self-reported leisure time physical activity (Fig. 4A) (control-baseline: $24.9 \pm 25.7$; midpoint: $19.6 \pm 12.5$; follow up: $12.8 \pm 17.5$; intervention-baseline: $13.0 \pm 8$ 0.6; midpoint: $26.3 \pm 16.1$; follow up: $26.0 \pm 14.6$ ), while also significantly mitigating increases in fatigue (control-baseline: $14.4 \pm 15.9$; midpoint: $19.0 \pm 11.4$; follow up: $29.4 \pm 20.0$; intervention-baseline: $29.2 \pm 24.6$; midpoint: $24.6 \pm 14.4$; follow up: $23.6 \pm 11.9$ ), and impairment of daily activities (control-baseline: 13.7 \pm 16.0 ; midpoint: $32.8 \pm 17.0$; follow up: $58.6 \pm 27.9$; intervention-baseline: $38.7 \pm 31.8$; midpoint: $47.1 \pm 27.5$; follow up: $47.5 \pm 31.0$ ), observed in the control group (Fig. 4B,

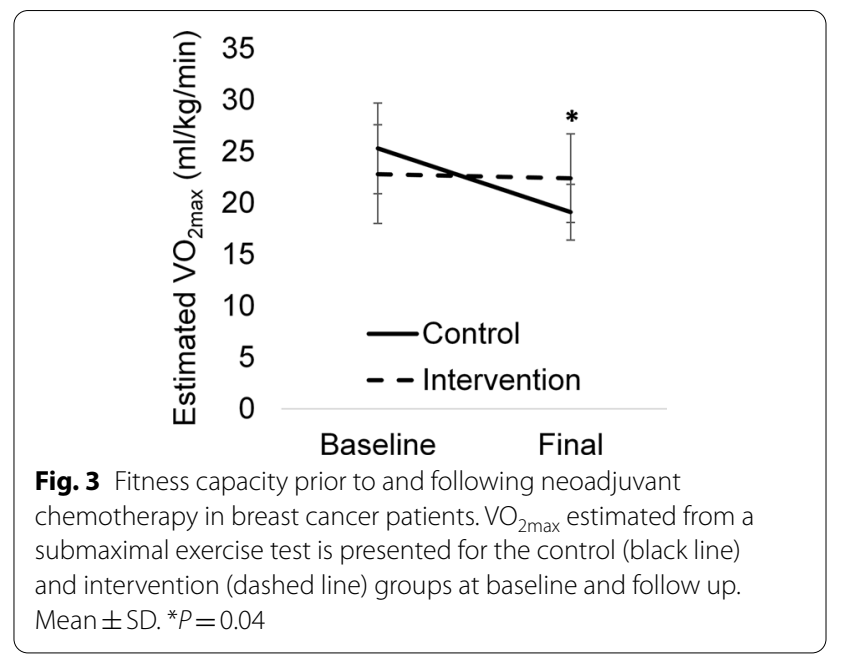

C). Higher scores on the SF-36 survey indicate more favorable outcomes. We observed that the intervention group had less pain (Fig. 4D) (control-baseline: $80.8 \pm 17.1$; midpoint: $73.9 \pm 20.7$; follow up: $50.7 \pm 25.7$; intervention-baseline: $68.7 \pm 28.4$; midpoint: $61.4 \pm 22.5$; follow up: $65.3 \pm 22.4)$, better physical function $(P=0.06$, Fig. 4E) (control-baseline: $89.4 \pm 11.3$; midpoint: $62.1 \pm 12.2$; follow up: $45.7 \pm 31.5$; intervention-baseline: $81.2 \pm 15.5$; midpoint: $73.6 \pm 13.1$; follow up: $66.9 \pm 16.7$ ), and less limitation in their role due to emotional limitations ( $P=0.09$, Fig. 4F) (control-baseline: $70.4 \pm 38.9$; midpoint: $80.9 \pm 32.5$; follow up: $57.1 \pm 31.7$; intervention-baseline: $66.7 \pm 47.1$; midpoint: $85.7 \pm 37.8$; follow up: $85.7 \pm 37.7)$. Lastly, there were no significant differences in exercise adverse events (control: $0.9 \pm 0.9$; intervention: $0.7 \pm 0.8$ ), treatment delays (control: $55 \%$; intervention: $37 \%$ ), or pathological complete response (control: 67\%; intervention: 75\%) between groups.

\section{Discussion}

We conducted a multi-center pilot study to examine the acceptability, tolerability, feasibility, and efficacy of a moderate-to-vigorous, home-based, remotely delivered, exercise program in breast cancer patients beginning neoadjuvant chemotherapy. We hypothesized that an

Table 2 Tolerability of a ramped, moderate-to-vigorous intensity, exercise prescription with weekly tele-coaching

\begin{tabular}{lllll}
\hline & Exercise time $(\mathbf{m i n} / \mathbf{w k})$ & $\begin{array}{l}\text { Average HR during exercise } \\
\mathbf{( b p m )}\end{array}$ & Average HR prescribed (bpm) & $\begin{array}{l}\text { Exercise } \\
\text { time at Rx } \\
\text { HR (\%) }\end{array}$ \\
\hline Introduction phase & $64.2 \pm 6.8$ & $134.2 \pm 9.5$ & $122.7 \pm 13.3$ & $72.7 \pm 11.5$ \\
Intermediate phase & $67.1 \pm 5.7$ & $139.3 \pm 3.5$ & $141.9 \pm 12.3$ & $61.0 \pm 5.0$ \\
Maintenance phase & $66.0 \pm 10.4$ & $137.8 \pm 7.3$ & $149.0 \pm 11.5$ & $23.7 \pm 7.1$ \\
\hline
\end{tabular}

Mean \pm SEM for patients that progressed at least 2 weeks into the introduction phase $(n=6)$ 

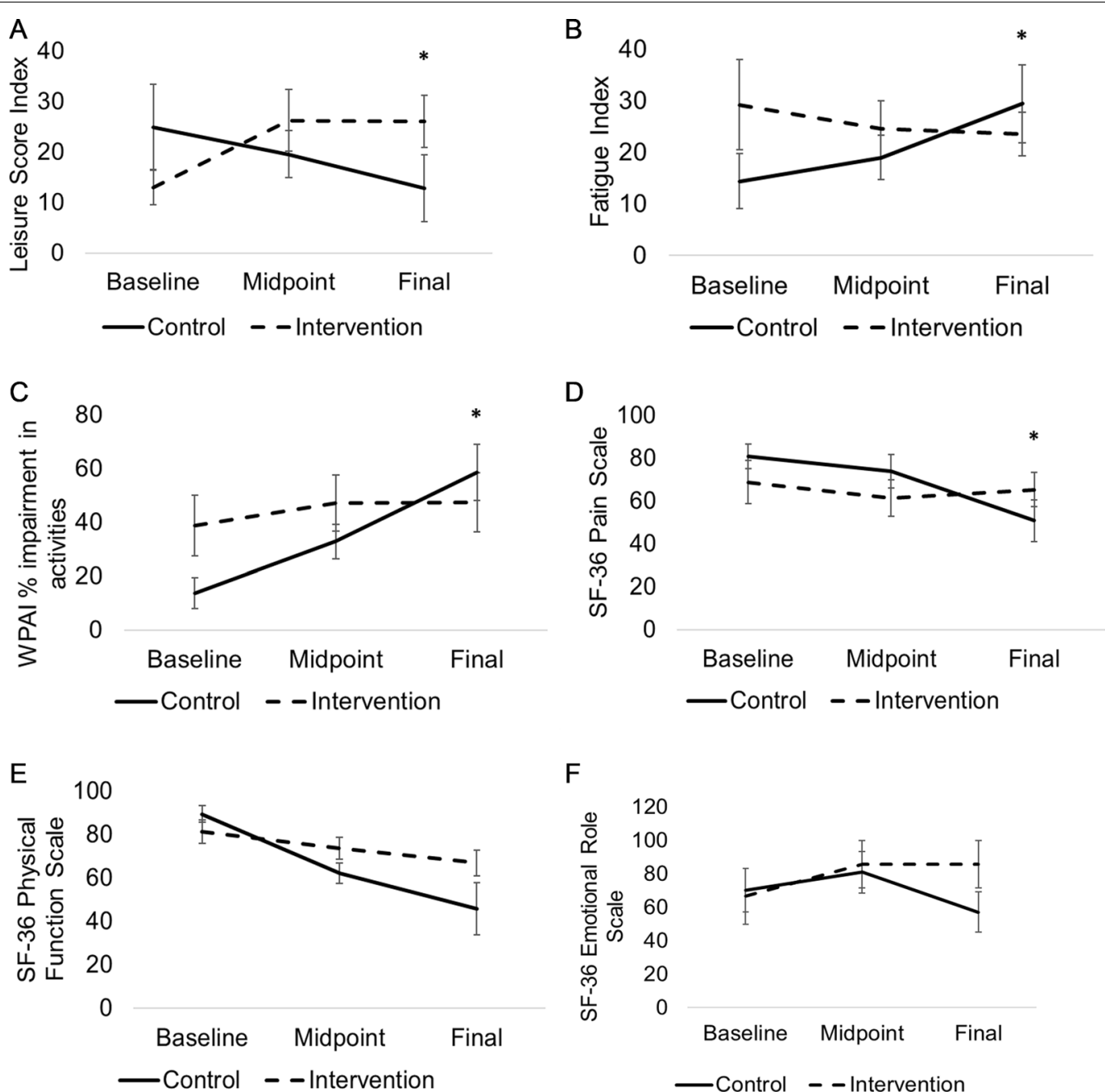

Fig. 4 Quality of life prior to, during, and following neoadjuvant chemotherapy in breast cancer patients. Leisure score index measured with the Godin Physical Activity Questionnaire (A), $P=0.03$, Fatigue Index from the MFSI-SF (B), $P=0.01$, impairment in regular daily activities measured with the Work Productivity and Activity Impairment (WPAI) Questionnaire $(\mathbf{C}), P=0.02$, and several scales derived from the RAND 36-Item Short Form (SF-36) such as pain (D), $P=0.02$, physical function $(\mathbf{E}), P=0.06$, and role of emotions in daily life $(\mathbf{F}), P=0.09$, are presented for the control (black line) and intervention (dashed line) groups at baseline, midpoint, and follow up. Mean \pm std. error mean. ${ }^{*} P<0.05$

individualized, phased, moderate-to-vigorous intensity, exercise prescription and weekly tele-coaching would be tolerable and improve fitness capacity. We observed that our exercise intervention maintained, but did not increase, fitness capacity in women receiving neoadjuvant chemotherapy. Women in the exercise intervention group maintained, on average, a moderate, but not vigorous, exercise intensity over the course of the exercise intervention. Further, while the flexibility built into our home-based, remotely delivered, individualized, exercise program was successful in keeping women adherent to the time component of our exercise dose, we observed limited tolerability of our exercise program for the intensity component of our exercise dose.
Our results indicate that approximately 65 min per week of moderate intensity aerobic exercise was sufficient to maintain fitness capacity. Similar to previous studies specifically conducted in breast cancer patients during cancer treatment, we observed that adherence to exercise training is high when the exercise prescription is flexible within a given set of a priori guidelines [31, 32]. Also, similar to previous work, high intensity aerobic exercise is difficult to maintain for breast cancer patients as chemotherapy cycles progress [33, 34]. Home based aerobic exercise interventions in breast cancer patients during chemotherapy (40-150 min/wk, moderate intensity, weekly calls, heart rate monitored) have been successful in maintaining or improving fitness capacity as measured 
by a 6 -min walk test, $[35,36]$ and have improved fatigue levels [36, 37]. However, unlike these studies, our intervention was conducted for the entire length of chemotherapy (16-24 weeks) and not limited to 8 , or 12 weeks $[21,38]$.

Disruptive world events such as the COVID-19 pandemic often spur medical innovation. Mobile health and remote communication technologies have become significantly more pervasive because of the pandemic. While the majority of our study was conducted prior to vast numbers of the population becoming comfortable with video chatting, we believe our home-based intervention would be conducive to an online lifestyle program. Indeed, the rapport created between interventionist and participant during such a challenging time as chemotherapy treatment would only be enhanced by video, rather than phone, conversations. Such an adaptation also could allow for synchronous coaching, to parallel, supervised interactions.

It is well established that fitness capacity, and change (increase or decrease) in fitness capacity, are powerful predictors of mortality in healthy adults as well as those with cardiovascular disease, even after controlling for traditional cardiovascular risk factors [16-18]. In a meta-analysis specific to breast cancer survivors, it was observed that the fitness capacity $\left(\mathrm{VO}_{2 \max }\right)$ of a 50 year old breast cancer survivor was most similar to that of a sedentary 60 year old woman [13]. Thus, exercise prescriptions during active treatment to mitigate declines in fitness capacity is clinically meaningful with regard to decreasing risk of overall and cardiovascular specific mortality in breast cancer patients. We observed that our control group decreased fitness capacity by $24.5 \%$, over double what has been reported previously in a meta-analysis [13]. Additionally, 4 years following completion of an exercise intervention during breast cancer treatment in 128 women, Witlox et al. observed that the standard of care control group had higher levels of fatigue and lower levels of physical activity compared to the intervention group [39]. Therefore, intervening during this treatment window may have durable effects in the long term.

Women recommended for neoadjuvant chemotherapy often have locally advanced tumors, HER2+ tumors, or TNBC [6]. As these tumor subtypes have the poorest prognosis in breast cancer patients, anxiety related to prognosis may significantly impact quality of life during treatment. While we primarily saw improvements in quality-of-life measures related to physical activity (physical function, impairment in daily activities, fatigue, leisure time activity), we also saw a trend for improvement in emotional limitations.

Our earlier studies indicated that breast cancer patients at the point of diagnosis have a strong desire for exercise programming following diagnosis [40]. However, we observed low acceptability (25.7\%) in neoadjuvant chemotherapy patients compared to similar studies conducted in the United States [21, 38]. Therefore, we may have experienced selection bias due to the large percentage of patients who declined to participate. We also experienced a low accrual rate which necessitated opening the trial to additional sites. Eligibility criteria may also have influenced our low accrual rate (e.g. restrictions related to coenrollment on other trials, and having a physical activity level above inclusion criteria). Depending on the primary aim of the exercise prescription in future trials, eligibility criteria (such as current physical activity level) can likely be discarded as exercise during treatment may improve efficacy of chemotherapy independent of current physical activity level. Some of the strengths of the study are also limitations. Many women cannot return to a center or clinic for supervised exercise training, yet, supervised exercise oncology interventions have demonstrated better adherence. While supervised exercise programs may have better adherence outcomes, [36] they are less feasible to deliver across sites or translate to implementation science [12]. Only about $12 \%$ of breast cancer diagnoses are recommended for neoadjuvant chemotherapy [41]. This limited our sample size, which is a limitation, and also limits generalizability to other breast cancer patients.

\section{Conclusion}

Our pilot study in neoadjuvant breast cancer patients was safe, improved quality of life, and demonstrated that approximately $65 \mathrm{~min}$ per week of home-based exercise is tolerable and effective in maintaining fitness capacity. Our remotely delivered exercise intervention utilized a phased approach to increase exercise intensity. It was difficult for patients to meet their tailored heart rate goals as both the intervention and their chemotherapy treatment course progressed. This indicates that it may be more efficacious to decrease the length of the introduction phase, and thus begin ramping patients to target intensities either as pre-habilitation or earlier in their treatment course prior to cumulative side effects of chemotherapy treatment. Larger trials may build on this pilot study and incorporate lessons learned. Ultimately, exercise training as an adjunctive therapy concomitant to chemotherapy may be utilized clinically for improved cancer outcomes. Potential implementation of exercise oncology in this regard will need to build on well-designed clinical trials which may find our feasibility study useful for such vertical translation.

\section{Abbreviations}

ER+: Estrogen Receptor positive; PR+: Progesterone Receptor positive; HER2-: Human Epidermal Growth Factor Receptor 2 negative; HER2+: 
Human Epidermal Growth Factor Receptor 2 positive; TNBC: Triple Negative Breast Cancer; ACSM: American College of Sports Medicine; MET: Metabolic Equivalent; mL/kg/min: Milliliter per kilogram per minute; PSCl: Penn State Cancer Institute; PA: Pennsylvania; A\&P: Andrews \& Patel; UPenn: University of Pennsylvania; TCH+P: Taxotere: Carboplatin: Herceptin + Perjeta; ACT: Adriamycin: cyclophosphamide: Taxol; min/wk: Minutes per week; $\mathrm{VO}_{2 \text { max }}$ : Maximal oxygen consumption; COVID-19: Coronavirus disease of 2019; UT: Utah; HR max: Heart rate maximum; RPE: Rating of perceived exertion; WPAl: Work Productivity and Activity Impairment Questionnaire; EQ-5D: EuroQol 5D; SF-36: RAND 36-Item Short Form; MFSI-SF: Multidimensional Fatigue Symptom Inventory; DVD: Digital Video Disc; US: United States; Inc.: Incorporation; NY: New York; CONSORT: Consolidated Standards of Reporting Trials; CPET: Cardiopulmonary exercise test.

\section{Acknowledgements}

Not applicable.

\section{Authors' contributions}

All authors read and approved the final manuscript. KMS: conceptualization, methodology, formal analysis, resources, data curation, writing, visualization, supervision, funding acquisition; AS: investigation, data curation, project administration; EF: investigation, editing, project administration; NK: investigation, writing; RK: methodology, data curation, investigation, supervision; EW: investigation, conceptualization; LC: supervision, conceptualization; BK: resources, editing, project administration; KHS: resources, editing, supervision. All authors read and approved the final manuscript.

\section{Funding}

This work was supported by the National Center for Advancing Translational Sciences (UL1 TR002014 and KL2TR002015 to Sturgeon); and by the National Cancer Institute of the National Institutes of Health under Award Number UG1CA189867. The content is solely the responsibility of the authors and does not necessarily represent the official views of the National Institutes of Health. The funding bodies were not involved in the design of the study, the data collection, analysis, or interpretation, or the writing of the manuscript.

\section{Availability of data and materials}

The datasets generated during and/or analyzed during the current study are available from the corresponding author on reasonable request.

\section{Code availability}

Not applicable.

\section{Declarations}

\section{Ethics approval and consent to participate}

The study was approved by the Penn State College of Medicine Institutional Review Board and we certify that the study was performed in accordance with the ethical standards as laid down in the 1964 Declaration of Helsinki and its later amendments or comparable ethical standards. Written informed consent was obtained prior to any study procedures.

\section{Consent for publication}

Not applicable.

\section{Competing interests}

The authors report no conflicts of interest.

\section{Author details}

${ }^{1}$ Department of Public Health Sciences, Penn State College of Medicine, Hershey, PA, USA. ${ }^{2}$ School of Medicine, University of Pennsylvania, Philadelphia, PA, USA. ${ }^{3}$ Department of Hematology/Oncology, Penn State College of Medicine, Hershey, PA, USA. ${ }^{4}$ Penn State Health Medical Group, Andrews Patel Hematology/Oncology, Harrisburg, PA, USA. ${ }^{5}$ Department of Public Health Sciences, Milton S. Hershey Medical Center, Penn State College of Medicine, Penn State Cancer Institute, 500 University Drive, mail code CH69, Hershey, PA 17033, USA.

Received: 29 June 2021 Accepted: 12 February 2022

Published online: 25 February 2022

\section{References}

1. Howlader N NA, Krapcho M, Miller D, Brest A, Yu M, Ruhl J, Tatalovich Z, Mariotto A, Lewis DR, Chen HS, Feuer EJ. SEER cancer statistics review. In: Ka C (ed). Bethesda: National Cancer Institute. 1975-2016.

2. Weiss A, Chavez-MacGregor M, Lichtensztajn DY, Yi M, Tadros A, Hortobagyi GN, Giordano SH, Hunt KK, Mittendorf EA. Validation study of the american joint committee on cancer eighth edition prognostic stage compared with the anatomic stage in breast cancer. JAMA Oncol. 2018:4:203-9. https://doi.org/10.1001/jamaoncol.2017.4298.

3. Group USCSW. U.S. Cancer Statistics Data Visualizations Tool, based on November 2018 submission data (1999-2016). In: U.S. Department of Health and Human Services CfDCaPaNCI (ed). 2019.

4. Hennigs A, Riedel F, Gondos A, Sinn P, Schirmacher P, Marme F, Jager D, Kauczor HU, Stieber A, Lindel K, Debus J, Golatta M, Schutz F, Sohn C, Heil J, Schneeweiss A. Prognosis of breast cancer molecular subtypes in routine clinical care: a large prospective cohort study. BMC Cancer. 2016;16:734. https://doi.org/10.1186/s12885-016-2766-3.

5. Sturgeon KM, Deng L, Bluethmann SM, Zhou S, Trifiletti DM, Jiang C, Kelly SP, Zaorsky NG. A population-based study of cardiovascular disease mortality risk in US cancer patients. Eur Heart J. 2019;40:3889-97. https:// doi.org/10.1093/eurheartj/ehz766.

6. William M, Sikov JCB, Al-Hilli Z. General principles of neoadjuvant management of breast cancer. In: Burstein HJ (ed) UpToDate. Waltham. 2020.

7. Schadler KL, Thomas NJ, Galie PA, Bhang DH, Roby KC, Addai P, Till JE, Sturgeon K, Zaslavsky A, Chen CS, Ryeom S. Tumor vessel normalization after aerobic exercise enhances chemotherapeutic efficacy. Oncotarget. 2016. https://doi.org/10.18632/oncotarget.11748.

8. Betof AS, Lascola CD, Weitzel D, Landon C, Scarbrough PM, Devi GR, Palmer G, Jones LW, Dewhirst MW. Modulation of murine breast tumor vascularity, hypoxia and chemotherapeutic response by exercise. J Natl Cancer Inst. 2015. https://doi.org/10.1093/jnci/djv040.

9. Sturgeon K, Schadler K, Muthukumaran G, Ding D, Bajulaiye A, Thomas NJ, Ferrari V, Ryeom S, Libonati JR. Concomitant low-dose doxorubicin treatment and exercise. Am J Physiol Regul Integr Comp Physiol. 2014;307:R685-692. https://doi.org/10.1152/ajpregu.00082.2014.

10. Khushhal A, Nichols S, Carroll S, Abt G, Ingle L. Insufficient exercise intensity for clinical benefit? Monitoring and quantification of a communitybased Phase III cardiac rehabilitation programme: a United Kingdom perspective. PLoS ONE. 2019;14:e0217654. https://doi.org/10.1371/journ al.pone.0217654.

11. Campbell KL, Winters-Stone KM, Wiskemann J, May AM, Schwartz AL, Courneya KS, Zucker DS, Matthews CE, Ligibel JA, Gerber LH, Morris GS, Patel AV, Hue TF, Perna FM, Schmitz KH. Exercise guidelines for cancer survivors: consensus statement from international multidisciplinary roundtable. Med Sci Sports Exe. 2019;51:2375-90. https://doi.org/10. 1249/MSS.0000000000002116.

12. Schmitz KH, Campbell AM, Stuiver MM, Pinto BM, Schwartz AL, Morris GS, Ligibel JA, Cheville A, Galvao DA, Alfano CM, Patel AV, Hue T, Gerber LH, Sallis R, Gusani NJ, Stout NL, Chan L, Flowers F, Doyle C, Helmrich S, Bain W, Sokolof J, Winters-Stone KM, Campbell KL, Matthews CE. Exercise is medicine in oncology: engaging clinicians to help patients move through cancer. CA Cancer J Clin. 2019;69:468-84. https://doi.org/10. 3322/caac. 21579.

13. Peel AB, Thomas SM, Dittus K, Jones LW, Lakoski SG. Cardiorespiratory fitness in breast cancer patients: a call for normative values. J Am Heart Assoc. 2014;3:e000432. https://doi.org/10.1161/JAHA.113.000432.

14. Lakoski SG, Barlow CE, Koelwyn GJ, Hornsby WE, Hernandez J, Defina LF, Radford NB, Thomas SM, Herndon JE 2nd, Peppercorn J, Douglas PS, Jones LW. The influence of adjuvant therapy on cardiorespiratory fitness in early-stage breast cancer seven years after diagnosis: the Cooper Center Longitudinal Study. Breast Cancer Res Treat. 2013;138:909-16. https://doi.org/10.1007/s10549-013-2478-1.

15. Barlow CE, Defina LF, Radford NB, Berry JD, Cooper KH, Haskell WL, Jones LW, Lakoski SG. Cardiorespiratory fitness and long-term survival in "lowrisk" adults. J Am Heart Assoc. 2012;1:e001354. https://doi.org/10.1161/ JAHA.112.001354.

16. Myers J, Prakash M, Froelicher V, Do D, Partington S, Atwood JE. Exercise capacity and mortality among men referred for exercise testing. N Engl J Med. 2002;346:793-801. https://doi.org/10.1056/NEJMoa011858. 
17. Erikssen G, Liestol K, Bjornholt J, Thaulow E, Sandvik L, Erikssen J. Changes in physical fitness and changes in mortality. Lancet. 1998;352:759-62. https://doi.org/10.1016/S0140-6736(98)02268-5.

18. Gulati M, Black HR, Shaw LJ, Arnsdorf MF, Merz CN, Lauer MS, MarwickTH, Pandey DK, Wicklund RH, Thisted RA. The prognostic value of a nomogram for exercise capacity in women. N Engl J Med. 2005;353:468-75. https://doi.org/10.1056/NEJMoa044154.

19. Jones LW, Liang Y, Pituskin EN, Battaglini CL, Scott JM, Hornsby WE, Haykowsky M. Effect of exercise training on peak oxygen consumption in patients with cancer: a meta-analysis. Oncologist. 2011;16:112-20. https://doi.org/10.1634/theoncologist.2010-0197.

20. Roger VL, Jacobsen SJ, Pellikka PA, Miller TD, Bailey KR, Gersh BJ. Prognostic value of treadmill exercise testing: a population-based study in Olmsted County, Minnesota. Circulation. 1998;98:2836-41.

21. Hornsby WE, Douglas PS, West MJ, Kenjale AA, Lane AR, Schwitzer ER, Ray KA, Herndon JE 2nd, Coan A, Gutierrez A, Hornsby KP, Hamilton E, Wilke LG, Kimmick GG, Peppercorn JM, Jones LW. Safety and efficacy of aerobic training in operable breast cancer patients receiving neoadjuvant chemotherapy: a phase II randomized trial. Acta Oncol. 2014;53:65-74. https://doi.org/10.3109/0284186X.2013.781673.

22. American College of Sports Medicine, Thompson WR, Gordon NF, Pescatello LS. ACSM's guidelines for exercise testing and prescription. Philadelphia: Lippincott Williams \& Wilkins; 2010.

23. Tanaka H, Monahan KD, Seals DR. Age-predicted maximal heart rate revisited. J Am Coll Cardiol. 2001;37:153-6. https://doi.org/10.1016/s07351097(00)01054-8.

24. Borg G, Dahlstrom H. A pilot study of perceived exertion and physical working capacity. Acta Soc Med Ups. 1962;67:21-7.

25. Amireault S, Godin G, Lacombe J, Sabiston CM. The use of the GodinShephard Leisure-Time Physical Activity Questionnaire in oncology research: a systematic review. BMC Med Res Methodol. 2015;15:60. https://doi.org/10.1186/s12874-015-0045-7.

26. Reilly MC, Zbrozek AS, Dukes EM. The validity and reproducibility of a work productivity and activity impairment instrument. Pharmacoeconomics. 1993;4:353-65. https://doi.org/10.2165/00019053-19930 4050-00006.

27. Stein $K D$, Jacobsen PB, Blanchard CM, Thors C. Further validation of the multidimensional fatigue symptom inventory-short form. J Pain Symptom Manag. 2004;27:14-23. https://doi.org/10.1016/j.jpainsymman.2003. 06.003 .

28. Ware JE Jr, Sherbourne CD. The MOS 36-item short-form health survey (SF-36). I. Conceptual framework and item selection. Med Care. 1992;30:473-83.

29. Warren M, Schmitz KH. Safety of strength training in premenopausal women: musculoskeletal injuries from a two-year randomized trial. Am 」 Health Promot AJHP. 2009;23:309-14. https://doi.org/10.4278/ajhp.07081 584.

30. Schmitz KH, Williams NI, Kontos D, Kurzer MS, Schnall M, Domchek S, Stopfer J, Galantino ML, Hwang WT, Morales K, Wu S, DiGiovanni L, Salvatore D, Fenderson D, Good J, Sturgeon K, Grant L, Bryan CJ, Adelman J. Women In Steady Exercise Research (WISER) Sister: study design and methods. Contemp Clin Trials. 2015;41:17-30. https://doi.org/10.1016/j. cct 2014.12016

31. Kirkham AA, Bland KA, Zucker DS, Bovard J, Shenkier T, McKenzie DC, Davis MK, Gelmon KA, Campbell KL. "Chemotherapy-periodized" exercise to accommodate for cyclical variation in fatigue. Med Sci Sports Exerc 2020;52:278-86. https://doi.org/10.1249/MSS.0000000000002151.

32. Kirkham AA, Bonsignore A, Bland KA, McKenzie DC, Gelmon KA, Van Patten $\mathrm{CL}$, Campbell KL. Exercise prescription and adherence for breast cancer: one size does not FITT all. Med Sci Sports Exerc. 2018:50:177-86. https://doi.org/10.1249/MSS.0000000000001446.

33. Huang HP, Wen FH, Tsai JC, Lin YC, Shun SC, Chang HK, Wang JS, Jane SW, Chen MC, Chen ML. Adherence to prescribed exercise time and intensity declines as the exercise program proceeds: findings from women under treatment for breast cancer. Support Care Cancer Off J Multinatl Assoc Support Care Cancer. 2015;23:2061-71. https://doi.org/10.1007/ s00520-014-2567-7.

34. Witlox L, Velthuis MJ, Boer JH, Steins Bisschop CN, Wall EV, Meulen W, Schroder CD, Peeters PHM, May AM. Attendance and compliance with an exercise program during localized breast cancer treatment in a randomized controlled trial: the PACT study. PLOS ONE. 2019;14:e0215517. https://doi.org/10.1371/journal.pone.0215517.

35. Cornette T, Vincent F, Mandigout S, Antonini MT, Leobon S, Labrunie A, Venat L, Lavau-Denes S, Tubiana-Mathieu N. Effects of home-based exercise training on $\mathrm{VO}_{2}$ in breast cancer patients under adjuvant or neoadjuvant chemotherapy (SAPA): a randomized controlled trial. Eur J Phys Rehabil Med. 2016;52:223-32.

36. van Waart $H$, Stuiver MM, van Harten WH, Geleijn E, Kieffer JM, Buffart LM, de Maaker-Berkhof M, Boven E, Schrama J, Geenen MM, Meerum Terwogt $J M$, van Bochove A, Lustig V, van den Heiligenberg SM, Smorenburg $\mathrm{CH}$, Hellendoorn-van Vreeswijk JA, Sonke GS, Aaronson NK. Effect of low-intensity physical activity and moderate- to high-intensity physical exercise during adjuvant chemotherapy on physical fitness, fatigue, and chemotherapy completion rates: results of the PACES randomized clinical trial. J Clin Oncol Off J Am Soc Clin Oncol. 2015;33:1918-27. https://doi. org/10.1200/JCO.2014.59.1081.

37. Huang HP, Wen FH, Yang TY, Lin YC, Tsai JC, Shun SC, Jane SW, Chen ML. The effect of a 12-week home-based walking program on reducing fatigue in women with breast cancer undergoing chemotherapy: a randomized controlled study. Int J Nurs Stud. 2019;99: 103376. https://doi.org/ 10.1016/j.jijnurstu.2019.06.007.

38. Lee K, Kang I, Mack WJ, Mortimer J, Sattler F, Salem G, Dieli-Conwright CM. Feasibility of high intensity interval training in patients with breast cancer undergoing anthracycline chemotherapy: a randomized pilot trial. BMC Cancer. 2019;19:653. https://doi.org/10.1186/s12885-019-5887-7.

39. Witlox L, Hiensch AE, Velthuis MJ, Steins Bisschop CN, Los M, Erdkamp FLG, Bloemendal HJ, Verhaar M, Ten Bokkel HD, van der Wall E, Peeters PHM, May AM. Four-year effects of exercise on fatigue and physical activity in patients with cancer. BMC Med. 2018;16:86. https://doi.org/10.1186/ s12916-018-1075-x.

40. Sturgeon KM, Fisher C, McShea G, Sullivan SK, Sataloff D, Schmitz KH. Patient preference and timing for exercise in breast cancer care. Support Care Cancer Off J Multinatl Assoc Support Care Cancer. 2018;26:507-14. https://doi.org/10.1007/s00520-017-3856-8.

41. Riedel F, Hoffmann AS, Moderow M, Heublein S, Deutsch TM, Golatta M, Wallwiener M, Schneeweiss A, Heil J, Hennigs A. Time trends of neoadjuvant chemotherapy for early breast cancer. Int J Cancer. 2020;147:304958. https://doi.org/10.1002/ijc.33122.

\section{Publisher's Note}

Springer Nature remains neutral with regard to jurisdictional claims in published maps and institutional affiliations.

Ready to submit your research? Choose BMC and benefit from

- fast, convenient online submission

- thorough peer review by experienced researchers in your field

- rapid publication on acceptance

- support for research data, including large and complex data types

- gold Open Access which fosters wider collaboration and increased citations

- maximum visibility for your research: over $100 \mathrm{M}$ website views per year

At BMC, research is always in progress.

Learn more biomedcentral.com/submissions 